Cell Research (2003); 13(2):131-139

http://www.cell-research.com

\title{
Isolation and functional characterization of the C-terminus of rice phosphatidylinositol 4-kinase in vitro
}

\author{
Xiang Feng Kong, Zhi Hong Xu, Hong Wei Xue*
}

National Laboratory of Plant Molecular Genetics, Institute of Plant Physiology and Ecology, Shanghai Institutes for Biological Science (SIBS),The Chinese Academy of Sciences; Partner Group el Max-Planck-Institute of Molecular Plant Physiology (MPI-MP) on "Plant Molecular Physiology and Signal Transduction",300 Fenglin Road, 200032 Shanghai, China

\begin{abstract}
A partial rice (Oryza sativa L.) cDNA clone, OsPI4Klc, was isolated through screening of a cDNA library constructed from tillering materials. OsPI4Klc encoded a peptide of 608 amino acids with a calculated molecular mass of $68.4 \mathrm{kDa}$. The OsPI4Klc peptide shared high homology and possessed the highly conserved domains present in most isolated cloned P14-kinases, i.e. a lipid kinase unique (LKU) domain and a catalytic (CAT) domain. A region with similarity to pleckstrin homology (PH) domain was present in OsPI4Klc as well. Further comparison with genomic sequences in databases revealed that OsPI4Klc is located at the 3 ' end of a putative rice PI 4-kinase coding gene OsPI4K1, and its coding region corresponded to the C-terminal half of OsPI4K1 protein. Twelve exons (49-562 bp in size) and 11 introns (77-974 bp in size) were identified in OsPI4K1c. The recombinant protein expressed in Escherichia coli phosphorylates phosphatidylinositol at the D4 position of the inositol ring. OsPI4K1 transcript levels were detected in a low but constitutive manner in shoot, stem, leaf, spike and root tissues and did not change upon treatment with different hormones, calcium and jasmonic acid (JA). However, treatment with salicylic acid (SA) elevated the mRNA level of the OsPI4K1 gene, which suggested the involvement of OsPI4Kl in wounding responses.
\end{abstract}

Key words: Oryza sativa, phosphatidylinositol 4-kinase.

\section{INTRODUCTION}

Phosphoinositides have been implicated in a vast range of cellular functions, including signal transduction, vesicle trafficking, endocytosis and cytoskeletal rearrangement, by which growth

\footnotetext{
* Corresponding author: Dr. Hong Wei XUE,

Tel: 0086-21-64042090 ext 4411, Fax: 0086-21-64042385,

E-mail: hwxue@iris.sipp.ac.cn

The abbreviations: PI, L- $\alpha$-phosphatidyl-1-D-myo-inositol; $\mathrm{PI}_{4} \mathrm{P}$, PI 4-phosphate; $\mathrm{PI}_{(4,5)} \mathrm{P}_{2}$, PI 4,5-bispbosphate; PI-PLC, phosphoinositide-specific phospholipase C; LKU, lipid kinase unique; $\mathrm{PH}$, pleckstrin homology; $\mathrm{PCR}$, polymerse chain reaction; PAGE, polyacrylamide gel electrophoresis; bp, base pair(s); kb, kilobase pair(s); EST, expressed sequence tag.

The nucleotide sequence(s) reported in this paper has been submitted to the GenBank ${ }^{\mathrm{TM}}$ / EMBL Data Bank with accession number AJ429217.

Received May-16-2002 Revised March-25-2003 Accepted March28-2003
}

factors, hormones and neurotransmitters can exert their physiological effects[1-4]. Sequential phosphorylation of the D3, D4 and D5 positions of L- $\alpha$ phosphatidvl-l-D-myo-inositol (PI) yields important signal molecules including PI 3,4-bisphosphate $\left[\mathrm{PI}_{(3,4)} \mathrm{P}_{2}\right], \mathrm{PI} 3,4,5$-trisphosphate $\left[\mathrm{PI}_{(3,4,5)} \mathrm{P}_{3}\right]$ and PI 4,5-bisphosphate $\left[\mathrm{PI}_{(4,5)} \mathrm{P}_{2}\right][5,6] . \mathrm{PI}_{(4,5)} \mathrm{P}_{2}$ is hydrolyzed by phosphoinositide-specific phospholipase $\mathrm{C}$ (PI-PLC) to the cellular messengers inosito1-1,4, 5 -trisphosphate $\left(\mathrm{IP}_{3}\right)$, a stimulator of calcium release from intracellular stores[7], and diacylglycerol (DAG), an activator of some protein kinase C isoforms[8]. Up to now, many of the components involved in PI signaling in animal cells have been identified but relatively few in plant cells[9]. In plants, besides their roles in calcium signalling, phosphoinositides have been implicated in a num- 
ber of environmental stress signaling processes, including responses to osmotic stress, light stress, pathogen attack, and in regulating plant leaf and flower development[10-13]. PI4P and $\mathrm{PI}_{(4,5)} \mathrm{P}_{2}$ are known to affect the activity of several enzymes, including the plasma membrane $\mathrm{H}^{+}$-ATPase[14] and phospholipase $\mathrm{D}[15]$ and can interact with cytoskeletal components[16]. Profilin is believed to be involved in cytoskeleton dynamics in plant cells through interaction with $\mathrm{PI}_{(4,5)} \mathrm{P}_{2}$ and actin as it is in animal cells[17].

The first step in the phosphorylation of PI in many receptor-dependent phospholipase C (PLC) and PI 3-kinase (PI3K) signaling pathways involves the synthesis of $\mathrm{PI}_{4} \mathrm{P}$ catalyzed by $\mathrm{PI} 4$ kinase[18]. So it represents a potentially crucial point of regulation of the phosphatidylinositol-dependent pathways. A number of PI 4-kinases catalyzing this reaction in animal and plant cells have been characterized biochemically. Two types (type II and III) of the enzyme, differing in size and sensitivity to detergents and adenosine, have been identified in a wide range of tissues and cellular compartments. These two PI4Ks differ from PI3K (originally termed as type I PI-kinase, for review see[3]).

The first cDNA encoding functional PI 4-kinase was isolated from Saccharomyces cerevisiae[19]. Putative PI 4-kinase clones have been identified in Schizosaccharomyces pombe, Dictyostelium discoideum, and Caenorhabditis elegans[20]. The proteins encoded by these genes have now been grouped into two distinct subfamilies, based on the homology with the yeast PI 4-kinase STT4 and PIKI $[9,20]$, of which the STT4 homologes have been assigned PI4-kinaseK and the PIK1 homologes PI4kinaseL[5, 21-23]. Comparison of the primary structures of these proteins has identified several conserved domains, i.e. a catalytic domain, a lipid kinase unique (LKU) domain and a $\mathrm{PH}$ domain. Catalytic domain contained about 250 amino acid residues and located at the $\mathrm{C}$-terminal of the proteins; LKU domain contained about 70 residues and located varies between the different isoforms. $\mathrm{PH}$ domain, which was a poorly conserved 100 amino acid motif that binds polyphosphorylated inositol lipids and thereby targets the protein in which it resides to the membrane[24, 25], only pre- sented in the larger isotorms of PI 4-kinase. It was noted that a novel repeat domain, which was highly charged, was presented in a $126-\mathrm{kDa}$ AtPI4K $\beta$ isoform from Arabidopsis thaliana though the function of the domain is unknown[26].

In plant cells, PI 4-kinase activity has been detected in different tissues including plasma membranes[27], cytosol[28], cytoskeleton[16] and nuclei [29]. The PI 4-kinase activity present in the plasma membrane of carrot cells responded to osmotic stress, cell wall-digesting enzymes, and light[30]. Up to now, two cDNAs, AtPI4K $\alpha$ [31] and AtPI4K $\beta 26$ ], which encoded plant PI 4-kinase have been isolated from A. thaliana. The encoded proteins comprised domains highly similar to the LKU and catalytic (CAT) domains of known PI 4-kinases. AtPI4K $a$ the larger isoform, had a PH domain and AtPI4K $\beta$ the smaller isoform, comprised a novel charged domain. Biochemical characterization of AtPI4K $\alpha$ and AtPI4K $\beta$ has shown their capacity to phosphorylate PI to $\mathrm{PI} 4 \mathrm{P}$, and the $\mathrm{PH}$ domain present in $\mathrm{AtPI}_{4} \mathrm{~K} a$ could bind phosphatidic acid (PA), PI4P and $\mathrm{PI}_{(4,5)} \mathrm{P}_{2}$. Here we report the isolation of a partial rice $\mathrm{cDNA}$ encoding a C-terminal part of PI4K and its functional characterization.

\section{MATERIALS AND NETHODS}

\section{Enzymes and chemicals}

Enzymes used for DNA restriction and modifications were from Roche (Boehringer Mannheim, Germany). DNA primers for polymerase chain reaction (PCR) were obtained from GENECORE Biotech (Shanghai, China). [ $\alpha{ }^{32}$ p]dCTP and $[\gamma-$ ${ }^{32}$ p]ATP were obtained from Yahui Company (Beijing, China). Phosphatidylinositol (PI) was purchased from Sigma.

\section{Bacteria and plants}

Escherichia coil strain XL-1 Blue (Stratagene) was used for DNA cloning procedures and for library screening. Seeds of rice (Oryza sativa L. cv. Zhonghua 11) were germinated on agarsolid MS medium and then grown in water in a phytotron with a $12 \mathrm{~h}$ light $\left(26^{\circ} \mathrm{C}\right)$ and $12 \mathrm{~h}$ dark $\left(18{ }^{\circ} \mathrm{C}\right)$ period. Two-week old plants were grown in water supplemented with different hormones and $\mathrm{JA}, \mathrm{CaCl}_{2}$, SA to the final concentration tested (see Fig 4) for $8 \mathrm{~h}$ and then used for RNA extraction.

\section{Construction of cDNA library using rice at tillering stage as materials}

$\mathrm{mRNA}$, isolated from the rice tillering tissue, was reverse transcripted to cDNA and the synthesized ds-cDNA was further ligated into $\lambda$ AP II vector (EcoRI pre-digested) according to the 
manufacturer' s instructions (Stratagene). Titer of the resulting cDNA library was around $10^{7} \mathrm{pfu} / \mathrm{ml}$.

\section{Isolation of tile OsPI4Klc cDNA and sequence analysis}

By searching for the nucleotide sequence homologous to AtPI4K $\beta$ (Accession No. AJ002685) in the EST database, one rice EST (locus D24350) was found. Specific primers, OsPI4KI1 (5'-CGCTGATGGTGGTTTATTAGAG-3') and OsPI4K1-2 (5'CATTGTTCCAGATGGATCAAGC-3'), were then designed according to the EST sequence and used to isolate the positive clones through cDNA library screening via PCR-based strategy [32]. Positive clones acquired were converted to pBluescript' $\mathrm{S}$ derivatives using helper phage Ex-Assist according to tile supplier' s (Stratagene) instructions. Clone pOsPI4Klc was used for further analyses.

DNA sequencing was done by GENECORE Biotech (Shanghai, China). Computational analysis, including "FASTA" and "BLAST" search program for sequence comparisons on DNA and amino acid sequences in GenBank ${ }^{\mathrm{TM}}$, EMBL, dbEST, and SwissProt databases, "PILEUP” program for sequence alignments and "BESTFIT" program for exon/ intron structure analysis, was performed with the help of the program “SeqWeb” (Version 2.0.2, Accelrys, Inc.).

\section{Expression of OsPI4KIc in E. coli and SDS-poly- acrylamide gel electrophoresis (PAGE)}

The expression vector pET32a(+) (Novagen, Germany) was used to express the rice OsPI4Klc in E. coli. The plasmid pET-His-PI4K was constructed as follows. The $1.8 \mathrm{~kb}$ DNA fragment isolated was amplified via PCR using forward (5'CATGCCATGGGAATGCTGGATCAGAACCAC-3', added Ncoi site underlined; start ATG of the OsPI4Klc-coding region in italics) and reverse (5'-CGGGATCCCTATTTCTCAATACCCTGC-3', added BamHI site underlined) primers. The amplified fragment was digested with NcoI and BamHI, then ligated into pET32a(+) predigested with same restriction enzymes to produce an expression plasmid. The amplified PCR fragment in the recombined plasmid pET-His-PI4K was sequenced to confirm that no nucleotide changes occurred during the PCR amplification. Transformed E. coli cells (strain AD494LysDE3) were grown at $37^{\circ} \mathrm{C}$ in liquid LB medium ( $1 \%$ bacto-tryptone, $0.5 \%$ bacto-yeast extract, $1 \% \mathrm{NaCI}, \mathrm{pH} 7.0$ ) containing appropriate antibiotics. Expression of recombinant OsPI4Klc was induced by addition of $1 \mathrm{mM}$ (final concentration) isopropyl-1-thio-? D-galactopyranoside (IPTG) at an $\mathrm{OD}_{600}$ reach of 0.3 , and the recombinant protein was extracted as follows: E. coli cells, grown for $6 \mathrm{~h}$, were harvest by centrifugation, and washed once with ice-cold phosphate- buffered saline ( $\mathrm{PBS}, 10 \mathrm{mM} \mathrm{Na} \mathrm{HPO}_{4}, 1.8 \mathrm{mM} \mathrm{KH}_{2} \mathrm{PO}_{4}, 0.14 \mathrm{M} \mathrm{NaCI}$, $2.7 \mathrm{mM}$ KCI, pH 7.3). Proteins were separated on 7\% SDS-polyacrylamide gels[33] and stained with Coomassie Blue 250. Protein concentrations were determined by the method of Lowry[34] using bovine serum albumin as standard.

\section{PI4-kinase activity assay}

The harvested E. cog cells, after a wash in PBS buffer (see above), were lysed by sonification in lysis buffer (containing 20 $\mathrm{mM}$ Tris/HCl, $\mathrm{pH}$ 7.4, $1 \mathrm{mM}$ EDTA, $150 \mathrm{mMNaC} 1,5 \mathrm{mM}$ dithiothreitol, $200 \mu \mathrm{m}$ 4-(2-aminoethyl)-benzenesulfonyl fluoride and $10 \%$ glycerol)[35]. Undisrupted cells were removed by centrifugation (12,000 rpm for $10 \mathrm{~min}$, Centrifuge 12043, Sigma) and the supernatant was analyzed by SDS-PAGE, or used tot activity measurements.

PI4-kinase activity was measured as incorporation of radioactivity from $\gamma^{32}$ p]ATP into organic solvent-extractable material. The standard reaction mixture for PI 4-kinase $(50 \mathrm{mM}$

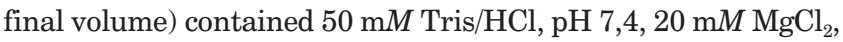
$1 \mathrm{mM}$ EGTA, $5 \mu \mathrm{m}$ PI, 0.2\% Triton X-100, $100 \mathrm{n} M\left[\gamma^{32} \mathrm{p}\right]$ ATP (>5000 Ci/mmol), and $0.2 \mu \mathrm{m}$ of extracted protein. All assay components except $\left[\gamma^{32} \mathrm{p}\right]$ ATP were preincubated for $10 \mathrm{~min}$ at room temperature and reactions were started by the addition of $\left[\gamma^{32} \mathrm{p}\right]$ ATP and terminated after $20 \mathrm{~min}$ by the addition of $0.8 \mathrm{ml}$ of cold chloroform/methanol/ $\mathrm{H}_{2} \mathrm{O}(1 / 2 / 0.8 ; \mathrm{v} / \mathrm{v} / \mathrm{v})$. The organic solvent phase was separated from $\left[\gamma^{32} \mathrm{p}\right]$ ATP by adding $0.4 \mathrm{ml}$ of chloroform/2.4N HC1 (1/1; v/v), mixing vigorously, and spinned for $1 \mathrm{~min}$ at 8,000 rpm. The upper (aqueous) phase was discarded, and an equal volume of chloroform/methanol/HC1 (5/245/235; $\mathrm{v} / \mathrm{v} / \mathrm{v}$ ) was added to the lower phase, followed by mixing and phase separation. An aliquot of the lower phase $(30 \mu \mathrm{l})$ was applied to thin-layer chromatography (TLC) plates (Silica gel 60 plates; Merck), Chromatograms were developed with a chloroform/methanol/concentrated NHa/H20 (45/35/2/8, v/v/v/v) solvent mixture. Plates were exposed to PhosphorImager (Molecular Dynamics, Inc., Sunnyvale, CA) overnight and then developed.

\section{Northern blot and reverse transcription-PCR (RT- $P C R$ ) analysis}

Total rice RNA, from different tissues of water-grown rice plants or rice shoots treated with hormones and chemicals, was extracted using Trizol reagent (Huashun, Shanghai) according to the manufacturer' $\mathrm{s}$ instructions.

Both Northern blot and RT-PCR were employed to detect the transcript levels of OsPI4K1 in various tissues or under treatment with hormones and chemicals. Total RNA was quantitated spectrophotometrically at $260 \mathrm{~nm}$. Denatured RNA $(30 \mu \mathrm{g})$ was loaded onto a 1.5\% agarose-formaldehyde gel[36] and transferred to Hybond- $\mathrm{N}^{+}$membranes (Amersham Pharmacia Biotech) after electrophoresis. RNA was fixed to the membrane via incubation at $80^{\circ} \mathrm{C}$ for $2 \mathrm{~h}$. A 1.5 -kb DNA fragment of the OsPI4Klc cDNA was used as $\left[\alpha-{ }^{32} \mathrm{P}\right] \mathrm{dCTP}$-labeled hybridization probe. Membranes were hybridized at $65{ }^{\circ} \mathrm{C}$ in $250 \mathrm{mM}$ sodium phosphate buffer, $\mathrm{pH} 7.2$, containing $7 \%$ SDS, $1 \%$ bovine serum albumin, and $1 \mathrm{mM}$ EDTA for at least $20 \mathrm{~h}$. Washes were performed at $65^{\circ} \mathrm{C}$ in $3 \times \mathrm{SSC}, 0.5 \% \mathrm{SDS}$ for $15 \mathrm{~min}$ and in $0.2 \times$ SSC, $0.5 \%$ SDS for $20 \mathrm{~min}$ [26]. Membranes were exposed to PhosphorImager for $24 \mathrm{~h}$ at room temperature.

RT-PCR analysis was performed using a standard protocol. The first strand of cDNA was reverse transcripted using $3 \mu \mathrm{g}$ total RNA as template with oligo $\left(\mathrm{dT}_{18}\right)$ as primer and products were then used as templates for further PCR amplification using specific primers OsPI4Klc-1 and OsPI4Klc-2 (see above) in a final volume of $20 \mu \mathrm{l}$ containing 0.5 unit Taq polymerase (Takara, 
China), $2 \mu$ l PCR buffer, $4 \mathrm{nM}$ dNTP, primers (10 pM each) and template. PCR reaction was performed as follows: $94^{\circ} \mathrm{C}, 2 \mathrm{~min}$ for denaturation; then $94^{\circ} \mathrm{C}, 45 \mathrm{sec}, 56^{\circ} \mathrm{C}, 50 \mathrm{sec}, 72^{\circ} \mathrm{C}, 40 \mathrm{sec}$ for 30 cycles, with a final extension at $72^{\circ} \mathrm{C}$ for $10 \mathrm{~min}$. Expression of rice actin 1 gene was used as internal control with primers actin1 (5'-GAACTGGTATGGTCAAGGCTG-3') and actin2 (5'ACACGGAGCTCGTTGTAGAAG-3').

\section{RESULTS}

\section{Cloning and sequence analysis of OsPI4Klc}

Rice EST (locus D24350), which was identified through a database search using A. thaliana AtPI4K $\beta[26]$ as bait, was used for design of specific primers for cDNA library screening via a PCR-based strategy. A cDNA clone, named OsPI4Klc, was isolated and sequence analysis showed a reading frame of 1827 nucleotides, which represented a 608-amino acid polypeptide with a calculated molecular mass of $68 \mathrm{kDa}$ (Fig 1), OsPI4Klc shared high homology to previously isolated PI4Ks and shared the highest homology with A. thaliana AtPI4K $a$. Blast search results further revealed a rice genomic fragment harbouring the entire OsPI4Klc coding region, present in a BAC clone (OSJNBa0018H01; GenBank Accession No. AC087181). The putative rice PI4K coding gene, named OsPI4K1, encoded a 1889-Aa polypeptide, indicating that the OsPI4Klc cDNA fragment we

\begin{abstract}
AGCTCAATTCATTIGAATTACATAGGCAAACGGGTGGGTGGTGGAACACATCCATAACATAATACTTATGAAAGAATCAACAATTGTAGCTACCAAAAGCTATACTTC TCAAACTTACGGTTCATCGCATCGCAGGCAAGTCAGCAACTTTGGTCATACGAACTCAGATGGACTITIACAGATTGAAACAATCAAAATGTTAAAAGAGGAAAAACAA ATTTCCCTCATGAGGCTCCGCTGTATCCTGAGCTGTAGCCACTGIAGCCGCCTCTCTTGGTTGTCCTGCTCTCAAAAGITTTGCTCAGAGAGAGGCCCAATCCGTGTC TATITGTCCATTGTCTACAAAATGAGCGCCCCAGTGGTTCTGCTGATTCTGCTCCGAAGTCACAGGGACGTGAAGGTGAACCCAATATGCTGGATCAGAACCACCCTG

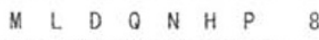
TGGGGCTCAGTGGATAACTATACAACTGTACGGGAAAAGCGTAAACAATTACTTCTTATGCTTTCTCAGAATGAGGCAGACAGACTTGAAGTGTGGGCACAACCGATA W G S V V D $N$ N Y TACAAAAGATGCAGCAACATTTCGTGGTAAAATTAGCTCAGATAAATGGATTGATCATGCCAGAACTGCTTTTGCTGTTGATCCTCGAATTGCATTCTCAATGATTAT

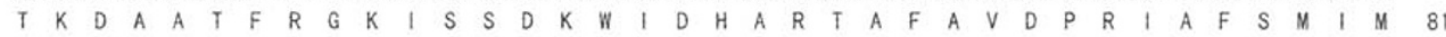
GGTTTCCCACAAACTCGGCATTATCATCAGAAATTACACAATTGGTACAGACACATATATTGGAACTCCGTACAATTCCTGAAGCATTACCCTTTTTCATCACTCCAA GCAGTAGATGAAAATTCATCATTGTTACAGCAACTTCCACATTGGGCTCCATGCTCTGTTACACAAGCATTGGAGTITCTTACCCCTCCTTATAAAGGACATCCCCGT A V D D E N $N$ S S S L L L Q Q L L P TATGGCATATGTTCTTCGTGTCCTGGAGACTTACCCACCTGAGACTGTTACCTTCTTTATGCCACAGTTGGTACAGTCTCTCAGATATGATGATGATAAATTGGTTGA

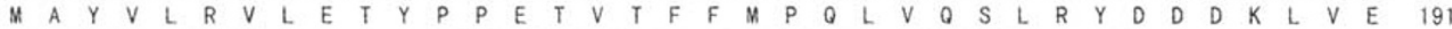

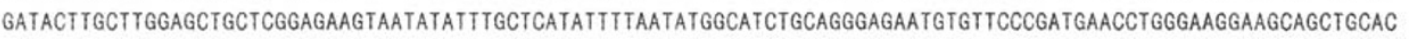

$Y$ L L G A A R R S N I F A H I L I W H L Q G E E C V P AAGGCCACTGCATTCCATTCCTTGCTTCCTGCCGTTAGGGAGAAAATTGTTGACGGTTTTACTCCAGAAGCTCGTGACATGTTTGAAAGAGAGTTCGAATTITTTGAC

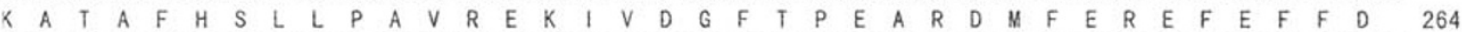
GGTCACCTCGATTTCTGGTGTTCTITITCCTCTTCCCAAAGAAGAGCGGCGAGCGGGTATTAAAAGGGAGCTGGAGAAGATTACTGTGCCAGGTGATGATCTGTACCT

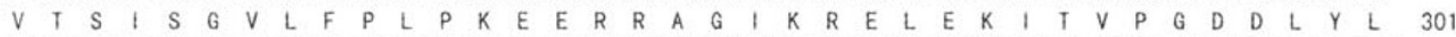
CTACTGCAACAAACAAGTTTGTACGGGGCATTCAAGTAGACAGTGGCATTCCTCTCCAGTCTGCTGCTAAAGTTCCAATAATGATTACTTTCAATGTGGTTGATCGTG

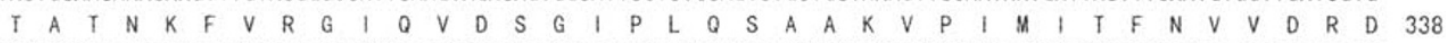
GGGGACCCAAACGATGTGAAGCCACAGGCTTGCATTTITAAGGTTGGTGATGATTGTAGACAGGATGTGCTGGCACTCCAAGTTATTGCTCTTCTAAGGGACATATTT

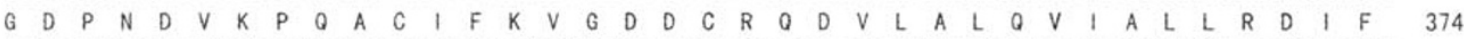
AGCTGTTGgATTAAACCTTTATCTCTTCCCATATGGTGTTTTACCCACTGGACCAGAGCGAGGCATAATTGAGGTGGTACCAAATACTCGGAGTAGAAATCAAATGGG

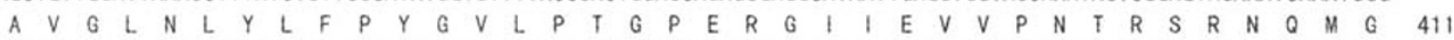
AAACAACTGATGGTGGTITATTAGAGATATTTCAGCAAGACTATGGCCCTGTAGGTTCACCTTCTITCGAAGCTGTTCGCGAAATGTTCATGATCAGTAGTGCTGGAT

$T$ T D G G L L E I F Q Q GCTGTTGCTAGCTTGCTTCTTCAGCCAAAGGATCGGCATAATGGCAATCTTCTCTITGATAGCCACGGGAGACTAGTCCATATTGATITTGGATTTATITTGGAGATT

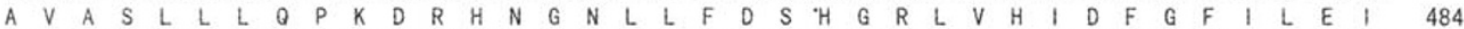
GCCTGGAGGAACATGGGGTTGGAAGTGCACATTTCAAGTTAAGCCATGAGATGACTCAATTGCTTGATCCATCTGGAACAATGAAGAGTGACACTTGGAATCAGTT

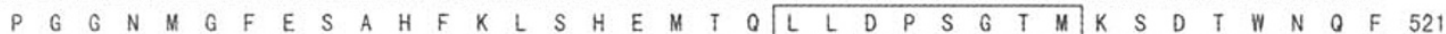
TGAGATTGTGTGTCAAAGGGTACCTAGCAGGAAGGAGACACATGAATGGGATTATTACTACCGTTAATTTGATGGTGGACAGTGGCCTGCCTTGCTTTAGCAGGGGAG

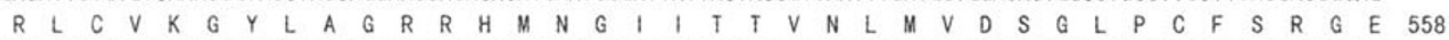
CCTATCGCTAATCTGCGAAAACGTITTCATCCAGAGATGAACGAGCGTGAGGCTGCTAATTITATGGTCAGAACATGTGTGGATGCCTACAACAAATGGACTACCGCA

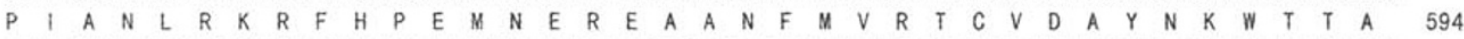
GTACGACTTGATTCAATACTTGCAGCAGGGTATTGAGAAATAGTCTATTTCTCCTTTTGTAAATGGGGGGTCGTGTACATCAATTGTATGTAGCCACTAATTCTTTTA

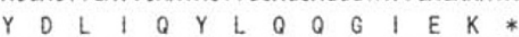
TAGAATTATGTTGTTGAGCGGTTCATTGTATGGTAAGAACGGTGATTTCAAGCGACTAACAGAGGGTGTATCAGTGTAAGTTAAACAGTGCCTATTCATITITITGTT ITTTGTAAGACAGCCGAGCTAGTAATTCTATTGGATCGCGTCTTACAGAACGAATGGGTCTTTGTATTGGCATGTGGATGTATTGTTATCTTCTTTTCGCGAATATGT ACATCTITITTCACTAAAAAAAAAAAAA
\end{abstract}

Fig 1. Nucleotide and predicted amino acid sequences of the partial cDNA clone encoding OsPI4Klc of Oryza sativa L. The PCR primers used to isolate tile cDNA were marked in square. The nucleotide sequence has been submitted to the GenBank ${ }^{\mathrm{TM}} / \mathrm{EMBL}$ Data Bank with accession number AJ429217. 
isolated correspondent to the 3 ' end of the OsPI4K1 coding region. The computer-predicted exon/intron structure of OsP14Klc was correct, based on the comparison of the cDNA with genomic sequence, which indicated the presence of 12 exons (49-562 bp in size) and 11 introns (77-974 bp in size) in OsPI4Klc. Mapping analysis indicated that the OsPI4K1 gene is located at the top of chrotnosome 3 .

\section{Structural organization of the OsPI4Klc peptide}

The deduced OsPI4Klc peptide possessed two regions highly homologous to the LKU and catalytic (CAT) domains of known PI 4-kinases (Fig 2A). Tile LKU domain in OsPI4Klc was located close to the $\mathrm{N}$ terminus and was $14-87 \%$ identical to those from previously identified PI 4-kinases. The $\mathrm{C}$ terminus of OsPI4Klc contained the putative CAT domain, which was $36-86 \%$ identical to the corresponding domains from other PI 4-kinases. In addition, the OsPI4Klc peptide has a domain, which is highly homologous with $\mathrm{PH}$ domain of $\mathrm{A}$. thaliana AtPI4K? a domain that characterizes members of subfamily 1.2 (Fig $2 \mathrm{~B}$ ). These data indicated that OsPI4K1 represented a new member of the subfamily 1.2 of PI 4-kinases, with a structure resembling most closely that of the yeast STT4 protein. In general, OsPI4K1 was most closely related to the PI 4-kinase of A. thaliana encoded by AtPI4K? with $79 \%$ identical and $88 \%$ similar amino acid residues.

Expression of recombinant OsPI4K1 c proteins in vitro and kinase activity assay

Based on the presence of LKU and CAT domain in OsPI4Klc, recombinant OsP14Klc was expressed with a polyhistidine tag at its $\mathrm{N}$ terminus in E. cob to investigate whether OsPI4Klc has PI 4-kinase activity. As shown in Fig 3A, a clear band appeared in the bacteria crude extract after induction with IPTG for $6 \mathrm{~h}$ (lane 2 and 3). Tile molecular mass of the recombinant OsPI4Klc protein was estimated to be $67-70 \mathrm{kDa}$, which closely agrees with the calculated molecular mass of 68 $\mathrm{kDa}$. The induced recombinant protein was further assayed for enzyme activity in vitro. After incubation in the presence of PI, the substrate of PI 4- kinase, recombinant OsPI4Klc yielded a phospholipid product on TLC plates, which co-

A
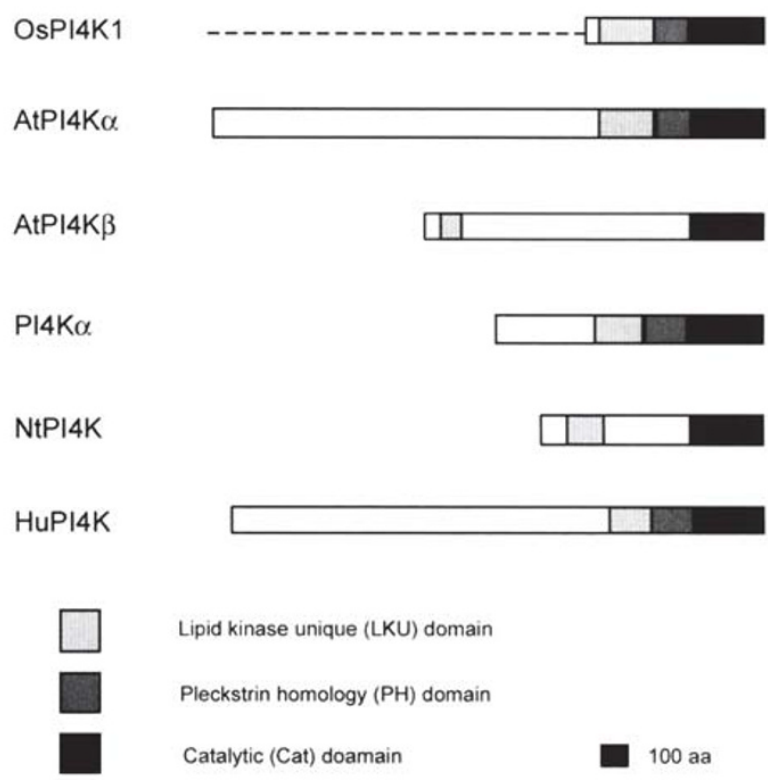

B

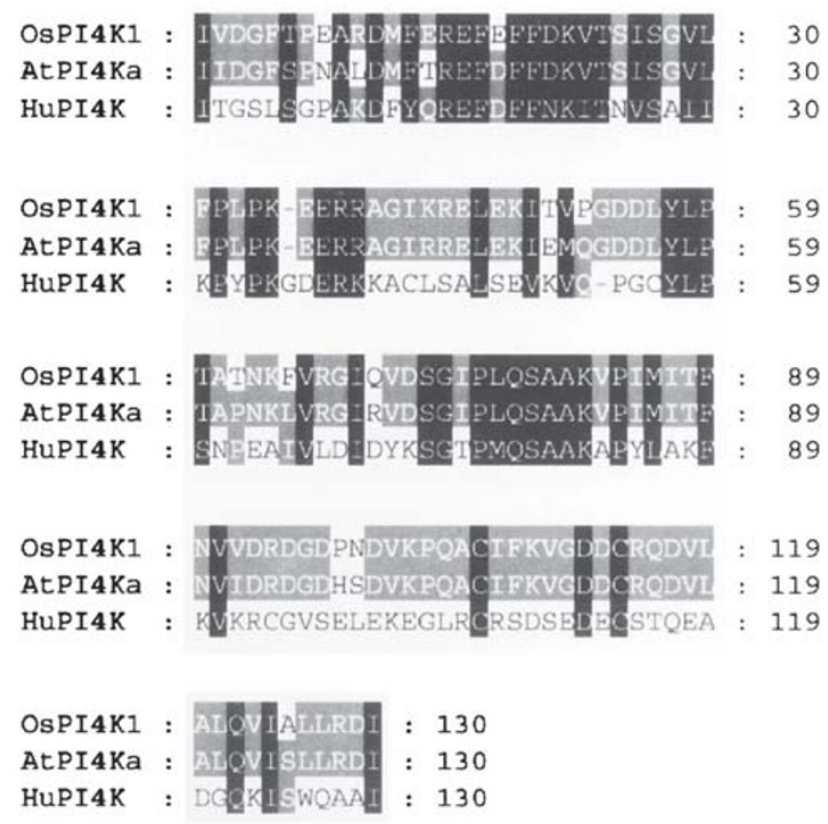

Fig 2. Structural organization of O. sativa PI 4-kinase I (OsPI4K1). A. Domain orgaafizations present in OsPI4K1, in comparison with selected PI 4-kinases. Accession numbers are as follows: AtPI4K $\beta$ (A. thaliana), AF035936; AtPI4K? (A. thaliana), AJ002685; PI4Kc $\alpha$ (human), L36151; NtPI4K (rat), D84667; HuPI4K (human), AF012872.

B. Multiple amino acid sequence alignment of the (putative) $\mathrm{PH}$ domain. 
chromatographed with authentic $\mathrm{PI}_{4} \mathrm{P}$ (Fig 3B), and the $32 \mathrm{P}$ in the chloroform phase was incorporated into $\mathrm{PI}_{4} \mathrm{P}$ only. These results showed that OsPI4K1c

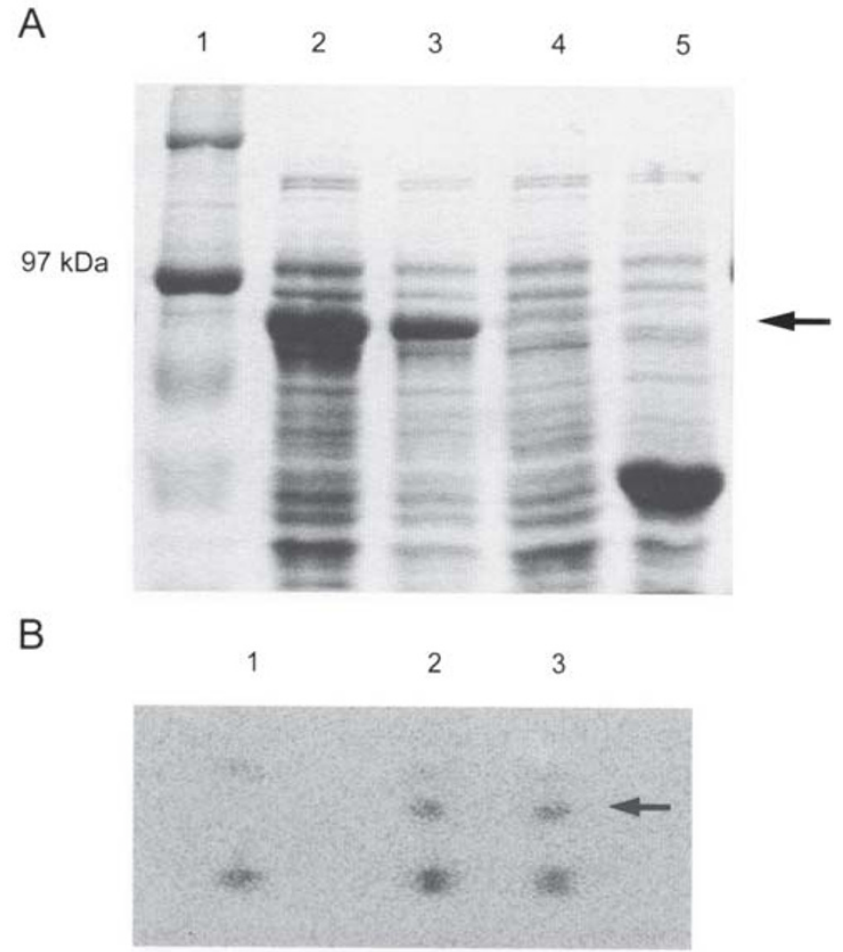

Fig 3. In vitro expression of OsPI4Klc and PI4K activity measurement of recombinant protein

A. Crude extract of E. coli cell after induction with $1 \mathrm{mM}$ IPTG for $6 \mathrm{~h}$ was separated on 10\% SDS-PAGE gel. Lanel, protein marker; Lane 2-5, protein crude extract from E. coli cells harbouring different constructs: lane 2 and 3 , two independent induction of OsPI4Klc fused to a His-tag; lane 4, mock vector; lane 5, a His-tag fusion plant protein unrelated to OsPI4K1. $100 \mu \mathrm{g}$ amount of total protein was loaded in lane 2 and $5 ; 40 \mu \mathrm{g}$ amount of total protein was loaded in lane 3 and 4. Arrow showed the production of recombinant OsPI4Klc. B. Analysis Of product produced by OsPI4Klc expressed in E. coli. Aliquots of PI4K assay mixtures were analyzed by TLC as described in Section 2 . The same amount $(0.2 \mu \mathrm{g})$ of total protein was used for each assay. Lane 1, the control protein from E. cob cells; lane 2 and 3, crude protein extract from E. coli ceils with independent induction. Arrow showed the production of PI4P, the product of PI 4-kinase.

indeed encodes a peptide with PI 4-kinase activity.

OsPI4K1 is constitutively expressed in various tissues at a low level and is up-regulated by salicylic acid (SA)

A $1.5 \mathrm{~kb}$ cDNA fragment of OsPI4Klc was used as hybridization probe to detect OsPI4K1 tran- script levels via Northern blot analysis. As shown in Fig $4 \mathrm{~A}$ top, a single band of similar intensity was detected in various tissues including roots, shoots, stems, leaves and spike tissues, which indicated a constitutive expression of OsPI4K1, however, the faint signals in Northern blot analysis revealed a relative lower level of OsPI4K1 in various tissues. Quantitative reverse transcription PCR was then employed and an identical result was obtained (Fig 4A bottom). Treatment with hormones including auxin, cytokinine, gibberellin (GA), abscisic acid (ABA), brassinosteroid (BR), jasmonic acid and

A

Root Shool Stem Leaf Spike

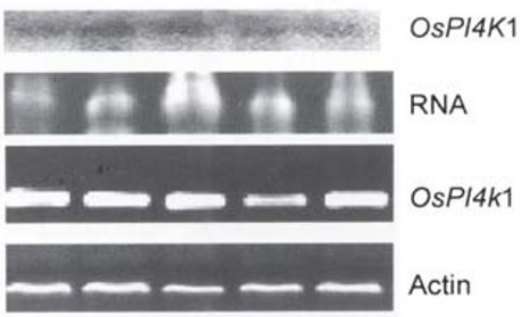

B

C.K. ABA BR CaCl KT GA IAA MJ SA

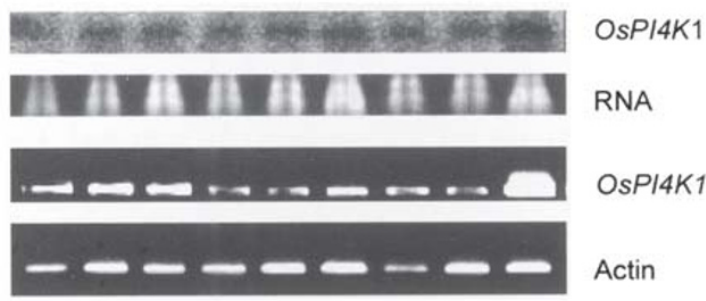

Fig 4. Expression analysis of OsPI4K1.

A. Expression pattern of OsPI4K1 in rice various tissues; B. Expression pattern of OsPI4K1 under treatment with plant hormones and salts. Northern blot (up) and RT-PCR (bottom) were carried out to detect the transcript of OsPI4K1. Rice actin was used as internal control as given in "material and method" OsPI4K1 transcript levels were tested in various tissues of rice. Roots and shoots were collected from 2 -weekold plants grown in water, and stems, leaves and spikes were from 7-week-old plants grown on soil. For the hormones and chemicals treatments, rice seedlings were grown in water for 2 weeks. Then the water was supplemented with one of the following compounds with final concentrations as indicated: abscisic acid (ABA; $10 \mu M)$; brassinosteroid (BR; $1 \mu M$ ); $\mathrm{CaCl}_{2}$ (5 mM); kinetin (100 pM); gibberellic acid (GA3; 100 pM); indole aceticacid (IAA; $10 \mu M$ ); jasmonic acid (JA; 100 $\mu M)$; salicylic acid $(200 \mu M)$. No additional compounds were added in the case of control experiments. After $8 \mathrm{~h}$ the shoots of rice were harvested and frozen in liquid nitrogen prior to RNA isolation. 
salts including sodium $(\mathrm{NaCl})$ and calcium $\left(\mathrm{CaCl}_{2}\right)$ had no effect on OsPI4K1 mRNA levels, while salicylic acid (SA) obviously increases the OsPI4K1 transcript level (Fig 4B).

\section{DISCUSSION}

In spite of a wide range of subcellular locations reported, only two genes encoding plant PI 4-kinase have been cloned[5, 37]. Both genes were isolated from A. thaliana, in which one encoded a polypeptide of $205 \mathrm{kDa}$ (AtPI4K $\alpha$ [38] and the other encoded a polypeptide of $126 \mathrm{kDa}$ (AtPI4K $\beta$ [26]. The OsPI4Klc reported in this study is the third cDNA encoding PI 4-kinase from plants and the first one in monocots. The OsPI4K1 polypeptide is highly homologous to C-terminus of AtPI4K $a(79 \%$ identical amino acids), and has a relatively low similarity to the other known plant isoform AtPI4K $\beta$ (41\% identity). According to the annotation of the released rice nuclear genome sequence, the OsPI4K1 gene encodes a protein of 1889 amino acids. The polypeptide encoded by OsPI4Klc contains all the conserved domains of PI4Ks including the CAT domain, the LKU domain, and the $\mathrm{PH}$ domain located between the CAT and LKU domains. The domain arrangement in OsPI4K1 resembles that of members of subfamily 1.2 of PI 4-kinases, which indicate that $\mathrm{OsP} 14 \mathrm{~K} 1$ is a new member of subfamily 1.2. It has been shown that AtPI4K $a$ by binding phosphoinositides at its $\mathrm{PH}$ domain, could be involved in the regulation of actin polymerization. It appears, thus, likely that the $\mathrm{PH}$ domain of type 1.2 PI 4-kinases is not responsible for substrate binding. Consequently, it is possible that substrate binding in PI 4-kinases is controlled by the LKU domain or a domain conserved structurally but not at the sequence level.

The recombinant protein expressed in E. coli phosphorylates phosphatidylinositol exclusively at the D4 position of the inositol ring. This result indicates that the C-terminal part of PI4K is sufficient, at least in vitro, for performing its catalytic activity though the function of the $\mathrm{N}$-terminus, i.e. approximately two thirds of the total protein, is still obscure. However, the research done by Gehrmann et a1[39] showed that proteins expressed either in E. coli or in eukaryotic cells containing only the highly conserved catalytic core of about 260 amino acids ( 28
$\mathrm{kDa}$ ) or additional extensions towards the $\mathrm{N}$-terminus up to $68 \mathrm{kDa}$ were inactive. The cause of the difference of the results might be the diversity of genes from various species, or more likely, the presence of LKU domain in OsPI4Klc. One can may assume that the weakly conserved $\mathrm{N}$-terminal part of the protein is important for stabilizing its structural configuration but not for substrate binding and catalytic activity.

In plant cells, PI 4-kinase activity is associated with the plasma membrane, nucleus, endomembranes, cytosol and the cytoskeleton[38]. This wide distribution in subcellular compartments implies that distinct pools of PI4P are targeted differentially to or synthesized in these subcellular compartments and might perform distinct physiological roles[38]. In higher plant cells the level of PI4P is up to 35-fold higher than that of $\mathrm{PI}_{(4,5)} \mathrm{P}_{2}[10,40]$, while in animal cells these phosphoinositides usually are present in approximately equal amounts. This feature may reflect a more central role of $\mathrm{PI}_{4} \mathrm{P}$ than $\mathrm{PI}_{(4,5)} \mathrm{P}_{2}$ in plant phosphoinositide-dependent processes compared with animal cells, in which the classical signal transduction pathway involving hydrolysis of $\mathrm{PI}_{(4,5)} \mathrm{P}_{2}$ catalyzed by phospholipase $\mathrm{C}$ perhaps is predominant[41]. Northern blot analysis showed that OsPI4K1 is constitutively expressed in various tissues, which may indicate an essential role of OsPI4K1 in rice growth and development. Previous studies have shown that the phosphatidylinositol signaling pathway is involved in many developmental processes[12, 13]. Hormone treatment and various environmental factors including salt and drought stress, as well as a hypersensitive reaction (HR) can stimulate the metabolism of phosphoinositides [42, 43] showed that salicylic acid probably acts through the phosphoinositide signal transduction system in cucumber. No change of OsPI4K1 expression under treatment with different plant hormones and chemicals indicated that the regulation by plant hormones and salt, $\mathrm{Ca}^{2+}$ of phosphatidylinositol signaling pathway didn抰 occurred in PI 4-kinase step. The strong induction of OsPI4K1 mRNA levels by salicylic acid suggested that, besides a function in the rearrangement of the cell cytoskeleton, the enzyme may be involved in the wound response in plant cells.

ACKNOWLEDGEMENT 
The study was supported by the State Key Project of Basic Research, No. G1999011604 and National Natural Science Foundation of China, No. 30100101. We would like to thank Prof. Bernd Mueller-Roeber (Potsdam University, Germany) for critical comments on the manuscript.

\section{REFERENCES}

1 Rana RS, Hokin LE. Role of phosphoinositides in transmembrane signaling. Physiol Rev 1990; T0:115-64.

2 Majerus PW, Ross TS, Cunningham TW, Cahtwell KK, Jefferson AB, Bansal VS. Recent insights in phosphatidylinositol signaling. Cell 1990; 63:459-65.

3 Tamas B. Phosphatidylinositol 4-kinases. Biochim Biophys Acta 1998; 1436:69-85.

4 Bruns JR, Ellis MA, Jeromin A, 揥eisz OA. Multiple roles for phosphatidylinositol 4-kinase in biosynthetic transport in polarized madin-darby canine kidney cells. J Bio Chem 2002; 277:2012-8.

5 Prmnan DA, Meyers RE, Cantley LC. Phosphoinositide kinases, Annu Rev Biochem 1998; 67:481-507.

6 Loewus FA, Murthy PPN. myo-Inositol metabolism ill plants. Plant Sci 2000; 150:1-19.

7 Berridge MJ. Inositol trisphosphate and diacylglycerol as second messengers. Bioehem J 1984; 220:345-60.

8 Nishizuka Y. Studies and perspectives of protein kinase C. Science 1986; 233:305-12.

9 Minogue S, Anderson JS, Waugh MG, Santos M, Corless S, Cramer R, Hsuan JJ. Cloning of a human type II phosphatidylinositol 4-kinase reveals a novel lipid kinase family. J Biol Chem 2001; 276:16635-40.

10 Sandelius AS, Sommarin M. Membrane-localized reactions involved in polyphosphoinositide turnover in plants. In W Boss, F Loewus, DJ Morr? eds, Inositol Metabolism in Plants. 1990; pp 139-161. Wiley-Liss, New York.

11 Dr鳰ak BK. The plant phosphoinositide system. Biochem J 1992; 288:697-712.

12 Cho MH, Shears SB, Boss WF. Changes in phosphatidylinositol metabolism in response to hyperosmotic stress in Daueus carota L. cells grown in suspension culture. Plant Physiol 1993; 103:637-47.

13 Monks DE, Aghoram K, Courtney PD, DeWald DB, Dewey RE. Hyperosmotic stress induces the rapid phosphorylation of a soybean phosphatidylinositol transfer protein homolog through activation of the protein kinases SPK1 and SPK2. Plant Cell 2001; 13:1205-19.

14 Memon AR, Chen QY, Boss WF. Inositol phospholipids activate plasma membrane ATPase in plants. Biochem Biophys Res Comnmn 1898; 162:1295-301.

15 Qin W, pappan K, Wang X-M. Molecular heterogeneity of phospholipase D (PLD). Cloning of PLD? and regulation of plant PLD? -? and -? by polyphosphoinositides and calcium. J Biol Chem 1997; 272:28267-73.

$16 \mathrm{Xu}$ P, Lloyd CW, Staiger C J, Dr?bak BK. Association of phosphatidylinositol 4-kinase with the plant cytoskeleton. Plant Cell 1992; 4:941-51.
17 Staiger C J, Gibbon BC, Kovar DR, Zonia LE. Profilin and actin-depolymerizing factor: modulators of actin organization in plants. Trends Plant Sci 1997; 7:275-81.

18 Pike LJ. Phosphatidylinositol 4-kinases and the role of polyphosphoinositides in cellular regulation. Endocr Rev 1992; 13:692-706.

19 Flanagan CA, Schnieders EA, Emerick AW, Kunisawa R, Admon A, Thorner J. Phosphatidylinositol 4-kiase: gene structure and requirement for yeast cell viability. Science $1993 ; 262: 1444-8$.

20 Gehrmann T, Ludwig MG, Heilmeyer JR. Phosphatidylinositol 4-kinases. Eur J Biochem 1998; 253: 357-70.

21 Yoshida S, Ohya Y, Goebl M, Nakano A, Anraku Y. A novel gene, STT4, encodes a phosphatidylinositol 4-kinase in the PKC1 protein kinase pathway of Saccharomyces cerevisiae. J Biol Chem 1994; 269:1166-71.

22 Ekblad L, Jergil B. Localization of phosphatidylinositol 4-kinase isoenzymes in rat liver plasma membrane domains Biochim Biophys Acta 2001; 1531:209-21.

23 Barylko B, Gerber SH, Binns DD, Grichine N, Khvotchev M, Siidhof TT, Albanesi JP. A novel family of phosphatidylinositol 4-kinases conserved from yeast to humans. J Biol Chem. 2001; 276:7705-8.

24 Lemmon MA, Ferguson KM, Schlessinger J. PH domains: diverse sequences with a common fold recruit signaling molecules to the cell surface. Cell 1996; 85:621-4.

25 Lemmon MA, Ferguson KM. Pleckstrin homology domains. Curr Top Mierobiol Immunol 1998; 228:3974.

26 Xue H-W, Pical C, Brearley C, Elge S, M黷ler-R鯁er B. A plant 126-kDa phosphatidylinositol 4-kinase with a novel repeat structure: cloning and functional expression in baculovirus-infected insect cells. J Biol Chem 1999; 274: 5738-45.

27 Sommarin M, Sandelius AS. Phosphatidylinositol and phosphatidylinositol phosphate kinases in plant plasma membranes. Biochim Biophys Acta 1988; 958:268-78.

28 Okpodu CM, Gross W, Burkhart W, Boss WF. Purification and characterization of a soluble phosphatidylinositol 4kinase from carrot suspension culture cells. Plant Physiol 1995; 107:491-500.

29 Hendrix KW, Assefa H, Boss WF. The polyphosphoinositides, phosphatidylinositol monophosphate and phosphatidylinositol bisphosphate, are present in nuclei isolated $\mathrm{fl}$ 抽m carrot protoplast. Protoplasma 1989; 151:62-72.

30 Memon AR, Boss WF. Rapid light-induced changes in phosphoinositide kinases and $\mathrm{H}^{+}$-ATPase in plasma membrane of sunflower hypocotyls. J Biol Chem 1990; 265: 14817-21.

31 Stevenson JM, Perera IY, Boss WF. A phosphatidylinositol 4-kinase pleckstrin homology domain that binds phosphatidylinositol 4-monophosphate. J Biol Chem 1998; 273:22761-7.

32 Alfandari D, Darribere T. A simple PCR method for screening cDNA libraries. PCR Methods and Applicaions 1994: 4:46-9. 
33 Laemmli UK. Cleavage of structural proteins during the assembly of the bead of bacteriophage T4. Nature 1970; 227:680-5.

34 Lowry OH, Rosebrough N J, Parr AL, Randall RJ. Prorein measurement with the Folin-Phenol reagents. J Biol Chem 1951; 193:265-75.

35 Zhao X-H, Bondeva T, Balla T. Characterization of recombinant phosphatidylinositol 4-kinase? reveals auto and heterophosphorylation of the enzyme. J Biol Chem 2000: 275:14642-8.

36 Logemann J, Schell J, Willmitzer L. hnproved method for the isolation of RNA from plant tissues. Anal Biochem 1987: 163:16-20.

37 Okpodu CM. Characterization of a nuclear phosphatidylinositol 4-kinase in carrot suspension culture cells. Plant Physiol Biochem 1999; 37:373-480.

38 Stevenson JM, Perera IY, Heilmann I, Persson S, Boss WF. Inositol signaling and plant growth. Trends in Plant Sci 2000; 5:252-7.
39 Gehrmann T, Giilkan H, Suer S, Herberg FW, Balla A, Vereb G, Mayr GW, Ludwig MG, Heilmeyer JR. Functional expression and chaxacterisation of a new human phosphatidylinositol 4-kinase PI4K230. Biochim Biophys Acta 1999; 1437:341-56.

40 Munnik T, Musgrave A, Vrije T. Rapid turnover of polyphosphoinositides in carnation flower petals. Planta 1994; 193:89-98.

41 Westergren T, Ekblad L, Jergil B, Sommarin M. Phosphatidylinositol 4-kinase associated with spinach plasma membranes: isolation and characterization of two distinct forms. Plant Physiol 1999; 121:507-16.

42 Atkinson MM, Bina J, Sequeira L. Phosphoinositide breakdown during the $\mathrm{K}+/ \mathrm{H}+$ exchange response of suspension-cultured tobacco cells to Pseudomonas syringae pv. Syringae. Mol Plant-Microbe Interact 1993; 6:253-60.

43 Li ZL, Yuan YB, Liu CL, Cao ZX. Studies of signal transduction of salicylic acid in cucumber cells. Acta Botanica Sinica 1998: 40:430-6. 